\title{
Metástasis ganglionares de carcinoma epidermoide en cuello con tumor primario desconocido: ¿aún existen en la época actual?
}

\author{
Node metastases of epidermoid carcinoma in the neck with unknown primary tumor: in \\ the current era does it still exist?
}

\section{José F. Gallegos-Hernández*}

Departamento de Tumores de Cabeza y Cuello, Hospital de Oncología, Centro Médico Nacional Siglo XXI, Instituto Mexicano del Seguro Social, Ciudad de México, México

Se integra el diagnóstico de metástasis ganglionares de carcinoma epidermoide en cuello con primario desconocido cuando la biopsia de las adenopatías muestra una neoplasia epitelial y la evaluación clínica, endoscópica e iconográfica, la amigdalectomía y las biopsias de mucosas del área de la cabeza y el cuello efectuadas al azar no permiten identificar el sitio del cual se originaron dichas metástasis.

Históricamente se ha considerado que esto ocurre en el $5-10 \%$ de los pacientes así evaluados ${ }^{1,2}$.

Las causas por las cuales el tumor primario no se encuentra no son muy claras; las teorías que tratan de explicarlas son tres:

- Que el tumor primario sea tan pequeño (pero con alta capacidad para enviar metástasis ganglionares) que no sea posible detectarlo por ninguno de los métodos clínicos y paraclínicos de evaluación.

- Regresión inmunitaria del tumor posterior a haber enviado las metástasis a los ganglios cervicales.

- El origen de la neoplasia son los propios ganglios linfáticos cervicales.

Los pacientes con metástasis ganglionares de carcinoma epidermoide en cuello con primario desconocido tienen la neoplasia confinada a la región de la cabeza y el cuello en el $90 \%$ de los casos, por lo que la búsqueda sistemática y exhaustiva del tumor por debajo de las clavículas no resulta necesaria y es una práctica ya en desuso.
Tradicionalmente el diagnóstico de esta afección se efectuaba con exploración física, imagenología (generalmente tomografía computarizada), endoscopia con fibra flexible de vías respiratorias y digestivas altas, y biopsias al azar de la mucosa, incluyendo amigdalectomía; si en ninguno de estos estudios se identificaba el tumor primario, se hacía el diagnóstico de metástasis ganglionares de carcinoma epidermoide en cuello con primario desconocido, lo que implicaba para el paciente un tratamiento radical que consistía en radioterapia radical a ambos cuellos y sitios de probable tumor (irradiación panmucosa) o bien la asociación de quimio-radioterapia si la etapa era avanzada (metástasis voluminosas o múltiples).

Sin embargo, el progreso en el conocimiento de las neoplasias de cabeza y cuello, y el advenimiento de nuevas técnicas de imagen, han permitido, por un lado, limitar el tratamiento al riesgo individual de cada paciente, y por el otro, identificar un mayor número de tumores primarios y disminuir la frecuencia de pacientes con diagnóstico de "primario desconocido".

La evaluación con tomografía por emisión de positrones (PET), la determinación del virus del papiloma humano (VPH) en los ganglios metastásicos y la resección mucosa de la base de la lengua y la región vallecular por vía oral son los tres avances más importantes que han tenido impacto en esta afección. Con estos adelantos, ¿existe aún la posibilidad de que un tumor primario de cabeza y cuello permanezca

\footnotetext{
Correspondencia:

*José F. Gallegos-Hernández

Avda. Carlos Fernández Graef, 154, Consultorio150

Col. Contadero, Del. Cuajimalpa Fecha de recepción: 04-07-2018

C.P. 05300, Ciudad de México, México Fecha de aceptación: 24-08-2018

E-mail: gal61@prodigy.net.mx

DOI: $10.24875 / C I R U .18000553$
}

Cir Cir. 2019;87:133-135

Contents available at PubMed

www.cirugiaycirujanos.com 
desconocido y el paciente reciba el tratamiento clásico con la consecuente morbilidad?

El concepto de metástasis ganglionares de carcinoma epidermoide en cuello con primario desconocido fue acuñado mucho antes de la aparición de la PET con 18-fluorodesoxiglucosa (18-FDG), método de imagen que, aunque no está exento de falsos positivos, permite identificar aproximadamente un $44 \%$ de los tumores primarios que la clínica y la endoscopia no revelan ${ }^{3}$. La imagen con captación del radionúclido en cualquier área de la mucosa de la cabeza y el cuello identifica el sitio del primario y evita que los campos de radioterapia incluyan toda el área cérvico-facial; sin embargo, en torno a un $60 \%$ de los pacientes no tienen sitio de mayor captación o son falsos positivos y continúan con el diagnóstico de metástasis ganglionares de carcinoma epidermoide en cuello con primario desconocido.

El VPH es conocido como factor etiológico de las neoplasias epidermoides de cabeza y cuello y también como factor de buen pronóstico en pacientes no fumadores ni consumidores de etanol. El sitio de la mucosa donde más se expresa es la orofaringe, y se estima que aproximadamente el $83 \%$ de los casos de cáncer orofaríngeo están asociados al VPH, principalmente al tipo 16. Cabe señalar que el DNA del VPH también puede ser identificado en los ganglios metastásicos, y en la actualidad sabemos que la expresión del VPH en los ganglios metastásicos permite concluir que el origen del tumor es la mucosa orofaríngea homolateral y ofrecer radioterapia selectiva con objeto de disminuir la tasa de complicaciones y de secuelas 4 .

El virus de Epstein-Barr, al igual que el VPH, se identifica en las metástasis ganglionares cuando el tumor primario se encuentra en la nasofaringe. La presencia de un carcinoma poco diferenciado, indiferenciado o tipo linfoepitelioma asociado al virus de Epstein-Barr permite concluir que el origen es la mucosa nasofaríngea ${ }^{3}$.

Por último, el advenimiento de la cirugía robótica transoral (TORS, por sus siglas en inglés) ha permitido que la mucosa, sobre todo del área de la base de la lengua y vallecular, sea adecuadamente evaluada y sometida a mucosectomía. Este procedimiento identifica el carcinoma primario en aproximadamente el $80 \%$ de los pacientes ${ }^{5}$, pero esta tecnología aún no es muy utilizada y muchos centros oncológicos alrededor del mundo carecemos de ella.

La evaluación integral actual de los pacientes con metástasis ganglionares de carcinoma epidermoide debe incluir la inspección y la palpación de la mucosa oral y orofaríngea, PET con 18-FDG, endoscopia de vías respiratorias y digestivas altas con fibra óptica efectuando biopsia de los sitios de sospecha, determinación del $\mathrm{VPH}^{6}$ en los ganglios linfáticos metastásicos y biopsia al azar de mucosas incluyendo amigdalectomía; este procedimiento diagnóstico permite reducir el número de primarios desconocidos al mínimo, lo cual se traduce en un tratamiento selectivo de estos pacientes, cuyo pronóstico en general es bueno.

En la actualidad podemos decir que hemos hecho el diagnóstico de metástasis ganglionares de carcinoma epidermoide en cuello con primario desconocido cuando el paciente ha sido evaluado en forma integral, ya que la gran mayoría de lo que creíamos primarios desconocidos tienen su origen en la mucosa orofaríngea.

Cuando la TORS esté más integrada en el área oncológica de cabeza y cuello, probablemente el número de pacientes con metástasis ganglionares cervicales con tumor primario desconocido será muy escaso o inexistente.

El porcentaje de pacientes con metástasis de carcinoma epidermoide en cuello sin primario encontrado es mínimo si nos apegamos al diagnóstico integral; esta evaluación permite ofrecer un tratamiento menos radical, menos mórbido y oncológicamente adecuado.

\section{Conflicto de intereses}

El autor declara no tener conflicto de intereses.

\section{Financiamiento}

El autor declara no haber recibido financiamiento para el presente manuscrito.

\section{Responsabilidades éticas}

Protección de personas y animales. El suscrito, autor principal del presente editorial, José F. Gallegos Hernández, declara que el presente manuscrito no se ha basado en experimentos con humanos ni con animales.

Confidencialidad de los datos. El autor declara que ha seguido los protocolos de su centro de trabajo sobre la publicación de datos de pacientes.

Derecho a la privacidad y consentimiento informado. El presente editorial no incluye datos personales de paciente alguno y representa la opinión del 
autor basada en la evidencia de la literatura; por lo anterior, no se viola el derecho a la privacidad ni se requiere consentimiento informado.

\section{Bibliografía}

1. Greco FA, Hainsworth JD. Cancer of unknown primary site. En: De Vita Jr VT, Hellman S, Rosenberg SA, editores. Cancer. Principles \& practice of oncology. Philadelphia: Lippincott Williams \& Wilkins. 2001; p. 2337-560.

2. Granados VF, Medrano Guzmán R, Rodríguez CAS. Metástasis cervicales de primario desconocido. En: Rodríguez CAS, editor. Tumores de cabeza y cuello. México, D.F.: Manual Moderno. 2003; p. 243-52.
3. Gallegos HJF, Rosales SFG, Cruz El. Metastatic squamous cell carcinoma of the neck with unknown primary site. J Cancerol. 2015; 2:161-9.

4. Tiong A, Rischin D, Young RJ, Herschtal A, Solomon B, D'Costa I, et al. Unilateral radiotherapy treatment for $\mathrm{p} 16 /$ human papillomavirus-positive squamous cell carcinoma of unknown primary in the head and neck. Laryngoscope. 2018;128:2076-83.

5. Mackenzie K, Watson M, Jankowska P, Bhide S, Simo R. Investigation and management of the unknown primary with metastatic neck disease: United Kingdom National Multidisciplinary Guidelines. J Laryngol Otol. 2016;S2:S170-5.

6. Troussier I, Klausner G, Morinière S, Blais E, Faivre JC, Champion A, et al. Advances in the management of cervical lymphadenopathies of unknown primary: advances in diagnostic imaging and surgical modalities and new international staging system. Bull Cancer. 2018;105:181-92. 